\title{
Penerapan Teknologi Tepat Guna Dalam Upaya Peningkatan Produksi Pengrajin Bedak Dingin di Kelurahan Pesayangan Kab.Banjar
}

\author{
Fadlilaturrahmah ${ }^{11}{ }^{*}$, Hidayaturrahmah'), \\ Food and Pharmacy Analysis Department, Lambung Mangkurat University , Banjarbaru, \\ South Kalimantan, Indonesia \\ 1 fadlilaturrahmah@ulm.ac.id
}

\author{
Biology Department, Lambung Mangkurat University , Banjarbaru, South Kalimantan, \\ Indonesia \\ 3Rahmahidayahipb09@yahoo.com
}

Artikel diterima: 28-10-2019, direvisi: 20-11-2019, diterbitkan: 25-12-2019

\begin{abstract}
Abstrak
"Pupur dingin" atau bedak dingin merupakan kosmetika tradisional yang berbasis kearifan lokal Kalimantan Selatan yang telah digunakan oleh wanita Kalimantan sejak ratusan tahun silam. Selain digunakan sebagai perawatan kulit (skin care) dari sengatan matahari juga banyak diminati sebagai oleholeh khas Banjar Kalimantan Selatan. Pengrajin bedak dingin di kelurahan Pasayangan Kabupaten Banjar, masih bertahan untuk dapat memproduksi juga disebabkan karena ingin mempertahankan tradisi warisan dari orang terdahulu. Melihat potensi dari bedak dingin yang tidak hanya diminati masyarakat lokal tetapi juga diminati oleh masyarakat dari luar daerah berpotensi untuk dapat dikembangkan. Namun produksi bedak dingin apabila musim hujan tidak bisa dilakukan karena proses pengering sangat tergantung dengan sinar matahari. Oleh karena itu penerapan teknologi tepat guna (TTG) merupakan salah satu cara untuk meningkatkan jumlah produksi dari bedak dingin. Tujuan dari kegiatan penerapan TTG ini adalah untuk meningkatkan produktifitas mitra pengrajin bedak dingin di Desa Pasayangan, Kec. Martapura, Kab.Banjar melalui penerapan TTG berupa mesin pengering. Metode pelaksanaan program dimulai dari survey ke lokasi, sosialisasi program, dan pelatihan cara penggunaan mesin. Hasil yang diperoleh dari pengabdian masyarakat adalah mitra mampu menggunakan mesin pengering. Dengan penerapan teknologi tepat guna untuk pengrajin bedak dingin mampu meningkatkan produksi bedak dingin dan diharapkan dapat meningkatkan pendapatan.
\end{abstract}

Kata Kunci: Kosmetik Tradisional, Pengrajin, TTG

\begin{abstract}
"Pupur Dingin" or cold powder is a traditional cosmetics based on local wisdom of South Kalimantan that has been used by Kalimantan women for hundreds of years. Besides being used as a skin care from sunburn, it is also in great demand as souvenirs typical of Banjar, South Kalimantan. Cold-powder craftsmen in the village of Pasayangan, Banjar District, still survive to be able to produce also because they want to maintain the tradition of inheritance from the previous people. Seeing the potential of cold powder which is not only attractive to local communities but also attractive to people from outside the area has the potential to be developed. However, cold powder production when the rainy season can not be done because the drying process is very dependent on sunlight. Therefore the application of appropriate technology (TTG) is one way to increase the amount of cold powder production. The purpose of the TTG application is to increase the productivity of cold powder craft partners in Pasayangan Village,
\end{abstract}


Kec. Martapura, Kab. Banjar through the application of TTG in the form of a drying machine. The program implementation method starts from the survey to the location, program socialization, and training on how to use the machine. The results obtained from community service are partners able to use the dryer. With the application of appropriate technology for cold powder craftsmen, it is able to increase the production of cold powder and is expected to increase revenue.

Keyword: Traditional Cosmetics, Craftsman, TTG,.

\section{Pendahuluan}

Kosmetika merupakan salah satu kebutuhan sekunder yang semakin terus meningkat karena adanya keinginan manusia yang selalu ingin semakin cantik khususnya wanita. Jumlah penduduk sekitar 250 juta jiwa, menjadikan Indonesia pasar yang menjanjikan bagi perusahaan kosmetik. Menurut Global Bussiness Guide menyatakan bahwa di Indonesia, pertumbuhan volume penjualan industri kosmetik didongkrak oleh permintaan yang meninggi dari kelas menengah. Populasi perempuan Indonesia sebagai pengguna kosmetik kini telah mencapai 126,8 juta orang. Potensi industri kosmetik dalam negeri didukung melalui kekuatan sekitar 760 perusahaan yang tersebar di seluruh wilayah Indonesia, dengan menyerap tenaga kerja langsung sebanyak 75 ribu orang dan tenaga kerja tidak langsung 600 ribu orang atau dengan kata lain industri kosmetik tergolong padat karya (Kemenperin, 2018).

Adanya tren back to nature membuat industri kosmetik yang berbasis dari herbal berprospek cerah. Penggunaan kebutuhan sekunder kini berkembang produk yang dahulu hanya sebagai

menjadi kebutuhan primer, terutama bagi perempuan. Tren masyarakat menggunakan bahan baku alami semakin meningkat. Ini membuka peluang dan kreativitas industri kosmetik di dalam negeri. Data Kemenperin menyebutkan, omzet industri kosmetik tahun 2010 sebesar Rp 8,9 triliun dan naik menjadi Rp 10,4 triliun tahun 2011. Hal itu menyebabkan industri kosmetika yang berbasis herbal berpotensi untuk dikembangkan.

Bedak dingin adalah campuran tepung pati dengan bahan pengharum, kadang-kadang ditambah dengan bahan pelembab, penahan sinar ultraviolet dan antiseptik yang berbentuk butiran kecilkecil kering, memiliki warna dan aroma sesuai dengan komposisinya.. Bahan baku utama pada proses pembuatan bedak dingin adalah tepung beras. Menurut Soetrisno (1969), fungsi tepung beras adalah untuk menghaluskan kulit. Tahap-tahap pembuatan bedak dingin adalah pencampuran bahan, penggelintiran, dan pengeringan. Menurut Sari, proses pebuatan bedak dimulai dengan menggiling bahan yang akan dicampurkan dengan derajat kehalusan tertentu (Sari, 1983).

Penelitian Yulianti \& Binarjo (2010)

Jurnal Pengabdian Kepada Masyarakat MEDITEG

Volume 4, Nomor 2, Desember 2019

2 
ukuran partikel bedak dingin sangat mempengaruhi mutu dari bedak dingin yang dihasilkan (Yulianti \& Binarjo, 2010). Setelah diaduk rata, secara perlahan-lahan ditambahkan akuades sehingga berbentuk pasta. Adonan ini kemudian digelintir membentuk bulatan-bulatan kecil dan dikeringkan dengan cara menjemurnya (Susianti, 1985).

Tanaman bangkal merupakan tanaman khas dari Kalimantan Selatan yang dimanfaatkan bagian kulit batangnya sebagai bahan dari pembuatan "pupur dingin". Ekstrak etanol kulit batang bangkal memiliki efektivitas sebagai tabir surya (Rahmawanty dkk, 2017). Penggunaan "pupur basah" secara turun temurun telah dipercaya sebagai perawatan kulit (skin care) dari sengatan matahari.

Pasayangan adalah salah satu kelurahan yang terletak di Kecamatan Martapura, Kabupaten Banjar, Provinsi Kalimantan Selatan, Indonesia. Di kelurahan ini terdapat pengrajin pembuat "pupur basah" yang masih menjaga warisan leluruh budaya khas Banjar, Kalimantan Selatan. Pengrajin masih menggunakan peralatan tradisional untuk menghasilkan "pupur dingin" dan hanya mengandalkan cahaya matahari untuk proses pengeringan sehingga apabila dimusim penghujan pengrajin tidak bisa melakukan proses produksi. Dengan demikian penerapan teknologi tepat guna berupa mesin pengering diharapakan dapat meningkatkan produksi bedak dingin sehingga dapat meningkatkan pendapatan pengrajin.

\section{Metode}

Metode yang digunakan dalam pengabdian kepada masyarakat ini menggunakan beberapa metode yaitu dimulai dari survey ke lokasi, sosialisasi program, dan pelatihan cara penggunaan mesin. Survey ke lokasi dilakukan untuk identifikasi permasalahan dan kebutuhan masyarakat mitra. Sosialisasi progran dilakukan dengan berkoordinasi dengan mitra mengenai penerapan teknologi tepat guna yang akan diberikan disesuaikan dengan kebutuhan mitra. Pelatihan cara penggunaan mesin dilakukan dengan mendatangkan teknisi untuk menjelaskan cara pemakaian mesin pengering.

\section{Hasil dan Pembahasan}

Kelurahan pasayangan adalah salah satu kelurahan yang terletak di Kecamatan Martapura, Kabupaten Banjar, Provinsi Kalimantan Selatan, Indonesia. Di kelurahan ini terdapat beberapa pengrajin pembuat "pupur dingin" atau bedak dingin yang masih menjaga warisan leluruh budaya khas Banjar, Kalimantan Selatan. Mitra pengrajin memiliki 2 jenis produk dari bedak dingin, yaitu bedak dingin yang terbuat dari tepung beras dan dari tanaman bangkal. Bedak dingin yang terbuat dari tepung beras menghasilkan bedak dingin yang berwarna putih dan 
bedak dingin yang terbuat dari tanaman bangkal menghasilkan bedak dingin yang berwarna kuning. Untuk bedak dingin yang dibuat dari tepung beras, bahan baku dibuat dari beras yang ditepungkan kemudian dicampurkan dengan bahanbahan pewangi alami seperti daun pandan dan bunga mawar. Untuk bedak dingin yang terbuat dari tanaman bangkal yang digunakan adalah kulit batang dari tanamannya.

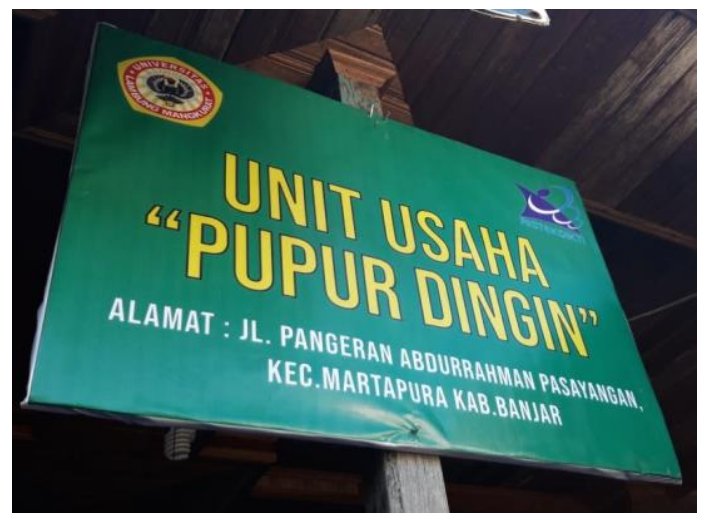

Gambar 1. Mitra Pengrajin Bedak Dingin

Cara pembuatan bedak dingin dari kulit batang bangkal dengan cara mengelupas kulit batang bangkal tanaman bangkal kemudian dipotong kecil-kecil dan dikeringkan. Kulit bangkal yang berwarna kuning ini lah yang menyebabkan bedak dingin dari bangkal berwarna kuning. Setelah itu, kulit batang bangkal dihaluskan menggunakan blender sehingga diperoleh dalam bentuk serbuk kemudian ditambahkan dengan tepung beras, bahan pewangi dan air. Kemudian adonan dibentuk menjadi bulat-bulatan yang berwarna kuning.

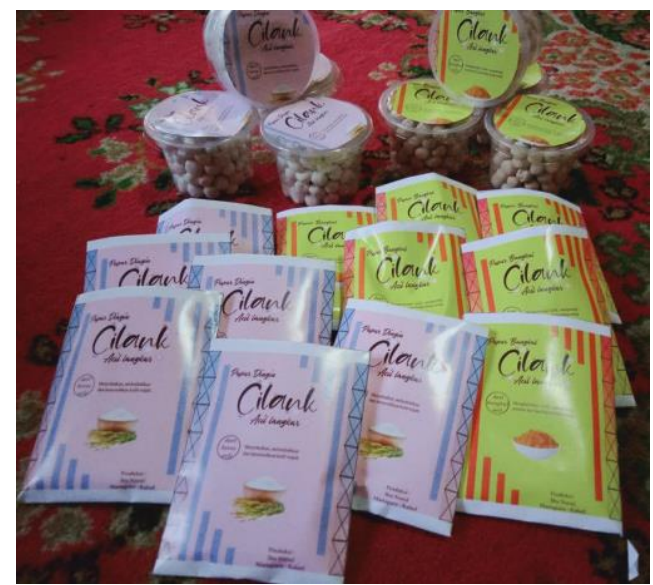

Gambar 2. Produk bedak dingin

dari tepung beras dan bangkal

mitra

Sosialisasi program penerapan teknologi tepat guna diberikan dengan cara menjelaskan bahwa program pengabdian menyediakan peralatan mesin pengering yang dapat digunakan untuk proses produksi bedak dingin sehingga proses produksi tidak hanya tergantung pada sinar matahari atau hanya pada musim panas saja. Dengan adanya penerapan teknologi tepat guna ini produksi dapat dilakukan sepanjang tahun tidak hanya pada musim panas saja. Pelatihan penggunaan mesin pengering dilakukan dengan cara melibatkan teknisi yang menjelaskan cara penggunaa mesin pengering tersebut. Pelatihan diawali dengan pemasangan sumber gas LPG untuk dapat menyalakan mesin pengering. Teknisi menjalaskan tahapan penggunaan mesin pengering. Untuk pemanasan bedak dingin, suhu mesin pengering yang digunakan adalah 60 derajad celcius (Depkes RI, 2009) agar komponen-komponen yang berkhasiat 
dari bahan-bahan pembuat bedak dingin tidak rusak oleh pemanasan .

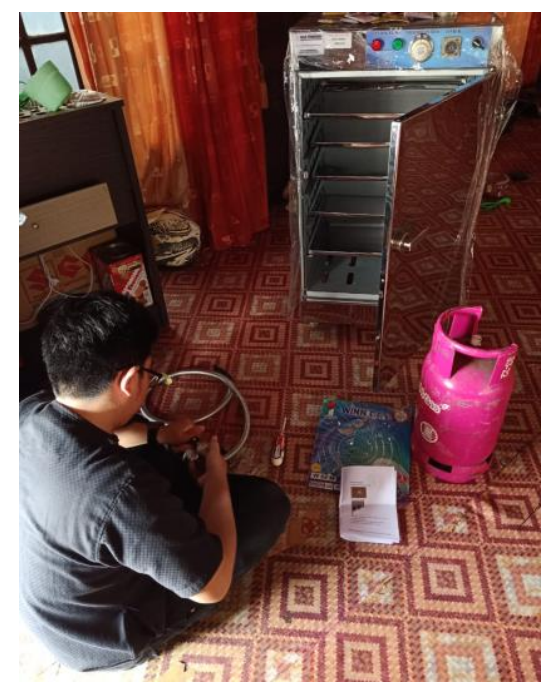

Gambar 3. Penjelasan teknisi cara penggunaan mesin pengering

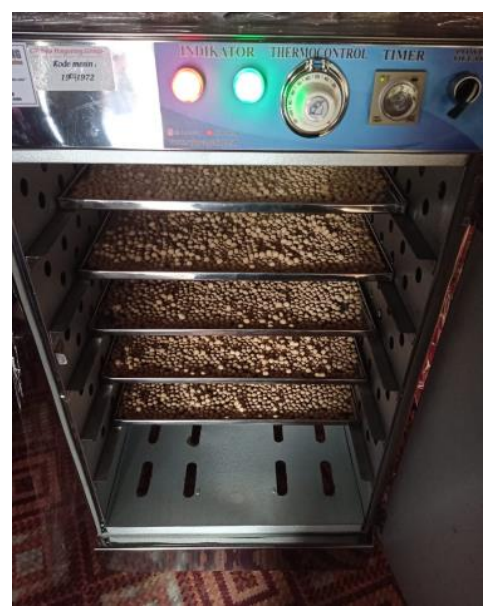

Gambar 4. Bedak dingin yang sedang dikeringkan menggunakan mesin pengering

Hasil dari kegiatan mitra mengetahui cara penggunaan mesin pengering sehingga dapat digunakan untuk mengeringkan bedak dingin. Produksi bedak dingin yang awalnya pada proses pengeringannya tergantung dengan keberadaan sinar matahari, dengan adanya mesin pengering produksi dapat dilakukan sepanjang tahun tanpa mengkhawatirkan proses pengeringan yang sulit pada musim penghujan.

\section{Penutup}

Penerapan teknologi tepat guna berupa mesin pengering dalam upaya peningkatan produksi pengrajin bedak dingin di kelurahan Pesayangan Kab.Banjar diharapkan dapat meningkatkan pendapatan pengrajin bedak dingin.

Saran yang diberikan untuk pengabdian kali ini adalah perlunya pendampingan kepada mitra dalam proses pemasaran bedak dingin yang dihasilkan.

\section{UCAPAN TERIMA KASIH}

Tim pengabdian masyarakat mengucapkan banyak terima kasih kepada Kemenristekdikti dan LPPM ULM atas dukungan material sehingga program pengabdian masyarakat ini dapat terlaksana.

\section{Daftar PUstaka}

Afriansyah, E.A. $\left(2012^{\mathrm{a}}\right)$. Design Research: Konsep Nilai Tempat dalam Operasi Penjumlahan Bilangan Desimal di Kelas V Dekolah Dasar. Tesis Magister pada SPS UNSRI-UTRECHT: Tidak diterbitkan.

Badan Standarisasi Nasional. (1992). SNI 
01-2973-1992. Syarat Mutu dan Cara

Uji Biskuit. Jakarta. Badan Standarisasi Nasional.

Dep. Perindustirian. (2003). Biskuit. Penanganan Gizi Buruk. Jakarta.

Hidayaturrahmah, Santoso H.B., Nurlely. (2016). Profil Glukosa darah tikus setelah pemberian ekstrak minyak ikan patin sebagai alternative antidiabetes. Laporan penelitan. Banjarbaru. DIPA FMIPA ULM.

Rimbawan, dan Siagian A. (2004). Indeks

Glikemia Pangan. Penerbit

Swadaya

Winarno, FG. (2002). Kimia Pangan dan

Gizi. Jakarta. Gramedia.

\section{Riwayat Hidup Penulis}

\section{Fadlilaturrahmah,M.Sc.Apt.}

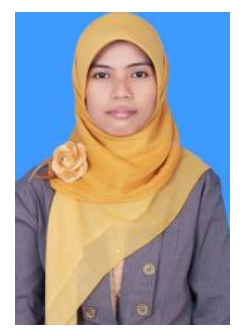

Lahir di Karang Intan, 8 Juni 1986. Penulis menyelesaikan program strata 1 dibidang farmasi pada program studi farmasi FMIPA Universitas Lambung Mangkurat, Banjarbaru pada tahun 2009 dan melanjutkan program profesi apoteker di Universitas Airlangga, Surabaya dan lulus pada tahun 2011. Pada tahun yang sama penulis melanjutkan program magister ilmu farmasi dengan konsentrasi Pengendalian Kualitas Obat dan Makanan pada Fakultas Farmasi Universitas Gadjah Mada, Yogyakarta serta lulus tahun 2013. Sejak lulus tahun 2013, penulis mengabdi kealmamater sebagai dosen di Universitas Lambung Mangkurat sampai sekarang.

\section{Hidayaturrahmah,M.Si.}

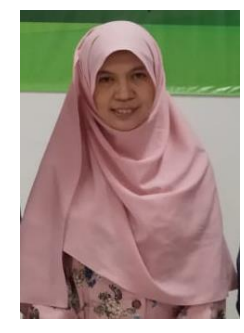

Lahir di Karang Intan, 14 Desember 1981. Penulis menyelesaikan program strata 1 pada program studi biologi FMIPA Universitas Lambung Mangkurat, Banjarbaru pada tahun 2004. Pada tahun yang sama penulis diterima sebagai dosen honorer ditempat penulis berkuliah. Kemudian penulis melanjutkan program magister di fakultas kedokteran hewan Institut Pertanian Bogor pada tahun 2009 dan mendapatkan gelar M.Si pada tahun 2011. Sekarang penulis aktif sebagai dosen di program studi Biologi, FMIPA, Universitas Lambung Mangkurat. 